\title{
Market Environment and Centralized Decision-Making and Their Impact on the Effectiveness of Organizations
}

\author{
Samir Aziz Al-Abbadi ${ }^{1}$ \\ ${ }^{1}$ Business Administration Department, Philadelphia University, Jordan \\ Correspondence: Samir Aziz Al-Abbadi, Business Administration Department, Philadelphia University, Jordan. \\ E-mail: s-abadi@philadelphia.edu.jo
}

Received: December 4, 2014

Accepted: December 24, 2014

Online Published: January 25, 2015

doi:10.5539/ibr.v8n2p129

URL: http://dx.doi.org/10.5539/ibr.v8n2p129

\begin{abstract}
This study is an applied attempt through which the approach of Contingency Theory in measuring the market's environment, centralized decision-making and the effectiveness of the organization is used. This particular theory is considered to be one of the most important theories that relates to modern organizations as it contributes to the explanation of organization's behavior and its employees. The present study measures the above mentioned variables and sheds light on the level of using Contingency Theory in the developing countries (Jordan). The study also explains some of the cultural and social concepts and implications and their impact on the results of the research. The research mainly includes two aspects; the theoretical one, which relates to the study concepts and its related literature, and the applied aspect that includes the methodology of the research and its conclusions. The study is mainly based on two major hypotheses and three minor ones. The major hypotheses are: The first major hypothesis states "decentralization correlates to the market environment that prevails in the working organization" The second major hypothesis states" the degree of co-alignment, among decentralization indicators represented by decision-making process and market environment, is incorporeally correlated to economical and behavioral effectiveness of the organization. For the purpose of examining the research model and its hypotheses, a sample of 30 Jordanian industrial organizations from to different industrial sectors in Jordan was selected and 106 managers holding senior management positions in their organizations were included in the study. Data of the study was obtained through personal interviews and questionnaires distributed to the managers of the targeted organizations and then Alpha Coefficient was calculated for centralization, effectiveness and environment. The hypotheses of the study were examined through depending on certain indicators related to centralization, effectiveness and environment. In addition, the hypotheses were examined through depending on significant statistical indicators such as Person and Spearman correlation coefficients as they are frequently used in such studies where they help to explain positive correlations between variables and present them in a clearer manner.
\end{abstract}

Keywords: contingency theory, market environment, centralized decision, effectiveness

\section{Introduction}

This study represents an applied attempt through which the approach of Contingency Theory in measuring the market environment, centralized decision - making and the effectiveness of the organization is used. This particular theory is considered to be one of the most important theories that relates to modern organizations as it contributes to the explanation of the behavior of both an organization and its employees. However, many scholars criticized this theory such as Pennings (1975), Child (1984) and Mansfield (1986). Those researchers mainly stated that the statement or logic of the theory needs more clarification, accuracy and consistent criteria .Based on this, the researchers recommended that more experimental studies should be conducted to examine the theory particularly the relationship between the market environment, being an important contingent variable, and the centralized decision-making process along with the effectiveness of the organization.

Based on this, the present study measures the relationship stated above and it explains the level of prevalence of contingency theory in the developing countries (Jordan). Also, the theory clarifies some of the social and cultural concepts and implications and their impact on explaining the results of the study. The research includes mainly two aspects; the theoretical aspect which focuses on the study concepts and its related literature as for the applied part, it highlights the methodology of the study, its results and conclusion. 


\section{Literature Review}

\subsection{Contingency Theory}

Contingency theory was known in the beginning of sixties in the last decade. The theory came as a response to the ideas called for by the classical and behavioral theories which analyze organizations in the market, This theory is based on the idea that the effectiveness of any organization in meeting its objectives depends on the degree of co alignment and consistency amongst all activities and actions of the organization and its contingent factors represented mainly by the size of technology and environment. Stalker and Burns (1961) Lawrence p.r and Lorsch (1967) and Thompson (1967) were the first pioneers who came up with these ideas. For example, Stalker and Burns (1996) conducted a study for ten industrial organizations in Scotland where they concluded that the change in market conditions (the environment of competitiveness) does affect the level of centralized decision- making process and the effectiveness of the organization. Within the same context, Lawrence and Lorsch (1967) studied the relationship between the structure of the organization and the change of its environment amongst a group of American industrial organizations. The study concluded that the level of centralized decision making affects the effectiveness of the organization in light of the constant changeable markets and the introduction of new developed technologies.

Therefore, the present study relied on the logic of this theory in order to measure the relationship between the market environment, centralized decision -making and effectiveness of the organization.

\subsection{Market Environment}

There has been a great interest recently among social and behavioral researchers in studying the environment and its impact on the effectiveness and functions of the organization. Many of these researchers such as Emerl and Trist (1965) Thompson (1967) Dill (1958) Child (1973) and finally Lawrence and Lorsch (1967) had succeeded in building up theoretical and applied models to identify the concept of environment and its different classifications. Generally, environment stands for all the external and internal factors that influence the activities of the organization. Hall and Mintzberg (1979) Although this definition presents a comprehensive meaning for the concept of environment, but it should be noted here that not all factors do influence the activities of the organization and if they do, they have different degree of effect. Hence, Dill (1958) introduced the concept of environment which is known to be the part that belongs to the overall environment of the organization and relates directly to identifying the goals of the organization and meeting them. Dill referred to components of environment represented by consumers, suppliers, employees, competitors and government rules and legislation. This concept of environment has led to three major approaches to study environment and its impact on the activities of the organization:

The first approach is the economical approach which classifies environment into a group of market sectors such as competitors, suppliers, consumers, stakeholders and owners. The major advocates for this approach were Negandhi and Elmann (1973) Pfeffer and Leblici (1973).

The second approach is the environmental data which focuses on the availability of the adequate data on environment that is necessary for decision-making process. This approach was adopted by Lawrence and Lorsch (1967) and Thompson (1967). The third approach is the one which depends on analyzing the different relationships that exist in the organization and their relevance to its environment through identifying the ability of the organization to gain capital and workers and through identifying the relationship between one organization and other ones. This approach is called Resource -Dependence. The major scholars who adopted such approach are Emerson, (1962) and Blan (1967).

On the other hand, Mansfield (1986) and Child (1984) suggested that environment should be handled in parts and each of the above mentioned approaches should be considered separately when studying them in relation to the structure of the organization and its effectiveness. So, the present study depends on the market approach when dealing with environment as market environment is defined as "a group of external factors that focus on the relationship between the organization and consumers" Negandhi and Rolmann (1972). Azma and Mansfield (1981) For the purpose of the study, environment market has been divided into three major components:

1) Degree of price competiveness among producers for the same products or goods.

2) Delay of delivering goods to consumers.

3) Level of providing alternative products for consumers.

It is worth mentioning that these three parts were referred to in the study of Negandhi and Rolmann (1972) in India, Boseman Jones (1974) in Mexico and Rolmann (1981) in Wales - Britain which proves the validity and 
reliability of including the three parts in this particular study.

\subsection{Centralization of Decision Making}

Centralization is one of the key dimensions in the organization structure. This concept was tackled by classical and modern theories that study organizations. Weber (1949) defined centralization when discussing the theory of bureaucracy inside the organization as "the degree of centralizing and authorizing managers of different levels in the process of making decisions inside the organization". Centralization of decision making is related to contingent factors represented by the size of the organization, technology and environment. The present study will focus on centralization indicators referred to by Negandhi and Rolmann (1976) Azma and Mansfield (1981) and Boseman and Jones (1976) representing the following:

1) The level of focus made by parties of authority on the process of decision making related to management policies such as production, marketing, financial aspects and individuals.

2) The level of employees' participation in decision making.

3) The participation of different levels of management in delivering and activating data and information to different levels.

\subsection{Organization Effectiveness}

Steers (1977) Etzini (1964) defined organization effectiveness as "the ability of the organization to achieve its goals". Pennings (1975) on the other hand, indicated that effectiveness is "the ability of the organization in creating a high level of consistency among the organization structure and its environment". It is worth mentioning that the present study adopts Steers' definition which focuses on the ability of the organization to achieve its goals supported by Goal- Model where effectiveness is divided into two types; the economical and the behavioral.

The behavioral effectiveness reflects the ability of the organization to:

1) Maintain workers of high skills.

2) Lift the spirits of the workers and their level of satisfaction.

3) Maintain good and positive relationships amongst the different departments of the organization.

4) Enhance strong relationships amongst colleagues and seniors.

5) Decrease the rate of workers' turn on and their absence.

6) Recruit competent mangers in senior positions.

As for the economical effectiveness, it represents the ratios of growth in sales and the capital revenues. These factors were used in different studied and applied in different environments such as the study of Negandhi and Rolmann (1972) in India and Boseman Jones (1981). In Mexico and that provides evidence for the validity of the criteria for measuring organization effectiveness.

\subsection{The Relationship between Market Environment, Centralization and Effectiveness}

This part of the study introduces the related literature that shed light on the contingent relationship between market environment, centralization and effectiveness of the organization. Burns and Stalker (1967) were the first scholars who studied this relationship where they focused on the relationship between market environment, representing its economic and technological aspects, and some indicators related to the structure of the organization (such as authority hierarchy and centralization of decision making). The researchers concluded that there are two organizational structures; organic and automated structures. Their study indicated the effectiveness of the organization increased in the changeable market environment when the organization adopts the organic structure (a high level of decentralization of decision -making). As for stable environments, organizations can resort to automated structure in order to increase the effectiveness of the organization for fulfilling the goals of the organization.

In America, Lawrence and Lorsch (1967) attempted to study the environment uncertainty (with regard to economic and technological changes) and its relationship with organizational structure and the effectiveness of the organization. They studied such relationship in some of the American industrial organizations where they concluded that successful and effective organizations working in dynamic environment tend to employ a high level of decentralization in decision making process compared with other organizations that work within a stable environment where such organizations tend to follow a high level of centralization in view to increase their effectiveness. 
Negandhi and Remain (1972) studied the above mentioned relationship in 30 industrial organizations in India. The study has come up with the idea that decentralization of decision making has direct relationship with the effectiveness of the organization within changeable or even stable market environments. The researchers stated that such relationship could be of a great value in the changeable market environment unlike the stable market environment. They also referred to their results being quite different from those of other studies and that is due to the different cultural, economic and social factors that prevail in the developing countries compared with those of the developed countries.

Boseman and Jones (1974) conducted the same study in twenty industrial organizations in Mexico though being a country with totally different history and culture. The researchers used the same tools employed in the previous study. The study concluded that centralization of decision making has direct relationship with the behavioral effectiveness of the organization in both changeable and stable market environments. Besides, they showed that there is a weak relationship between the decentralization of decision making and the economical effectiveness of the organization within changeable and stable market environments. The researchers justified that these results came to be different from those listed in the study of India simply because of factors related to bias and economic and cultural values that distinguish Mexico from India.

The same relationship was again addressed by Rimann (1976) but this time in 19 industrial organizations in Ohio. The study indicated that there is an incorporeal relationship between decentralization and the effectiveness of the organization in stable environments.

Finally, Azma and Mansfield (1981) studied 25 industrial organizations in Wales in the UK where they used the same criteria employed in the previous studies. The study concluded that there is a negative relationship between the decentralization of the organization and its behavioral effectiveness in changeable and stable environments and this also applies to the economical effectiveness. On the other hand, they criticized the contingency theory because of the inconsistency and contradiction of the results presented in different studies though using the same criteria. They also recommended that there should be more detailed studies on this particular and should field and should be conducted in different environments so that the validity of contingency theory can be examined highlighting the relationship between the market, centralized decision making and the effectiveness of the organization. Therefore, the researcher would remind readers here that he could not find recent studies on this particular topic as it has not been tackled yet in the developing countries.

\section{Study Objectives}

The present study sheds light on the contingent approach to address the above mentioned relationship through:

1) Examining the relationship between the effectiveness of the organization and the level of centralization of decision making particularly decisions related to management policies, involving employees in decision making and the delivery of data and information among all levels of management.

2) Examining the relationship between market environment and centralization of decision making and its implications on behavioral and economical effectiveness of the organization.

3) Explaining the implications of the theoretical and practical results of the research model.

\section{Research Model and Hypotheses}

Based on the review of related literature and the objectives of the study, the present paper proposes that the decentralization of decision making is related to the type of market environment whether stable or changeable. The model presented below suggests that the behavioral and economical effectiveness of the organization depends mainly on the co-alignment and consistency that exist between centralization and the environment of the market. Therefore, whenever the environment of the market seems to be changeable, the organization tends to adopt decentralization of decision making and it enhances the involvement of workers in decision making process and delivers data among them throughout all level of management. The organization applies this mechanism to achieve its goals. So, the relationships presented in the model below introduce two major hypotheses. 


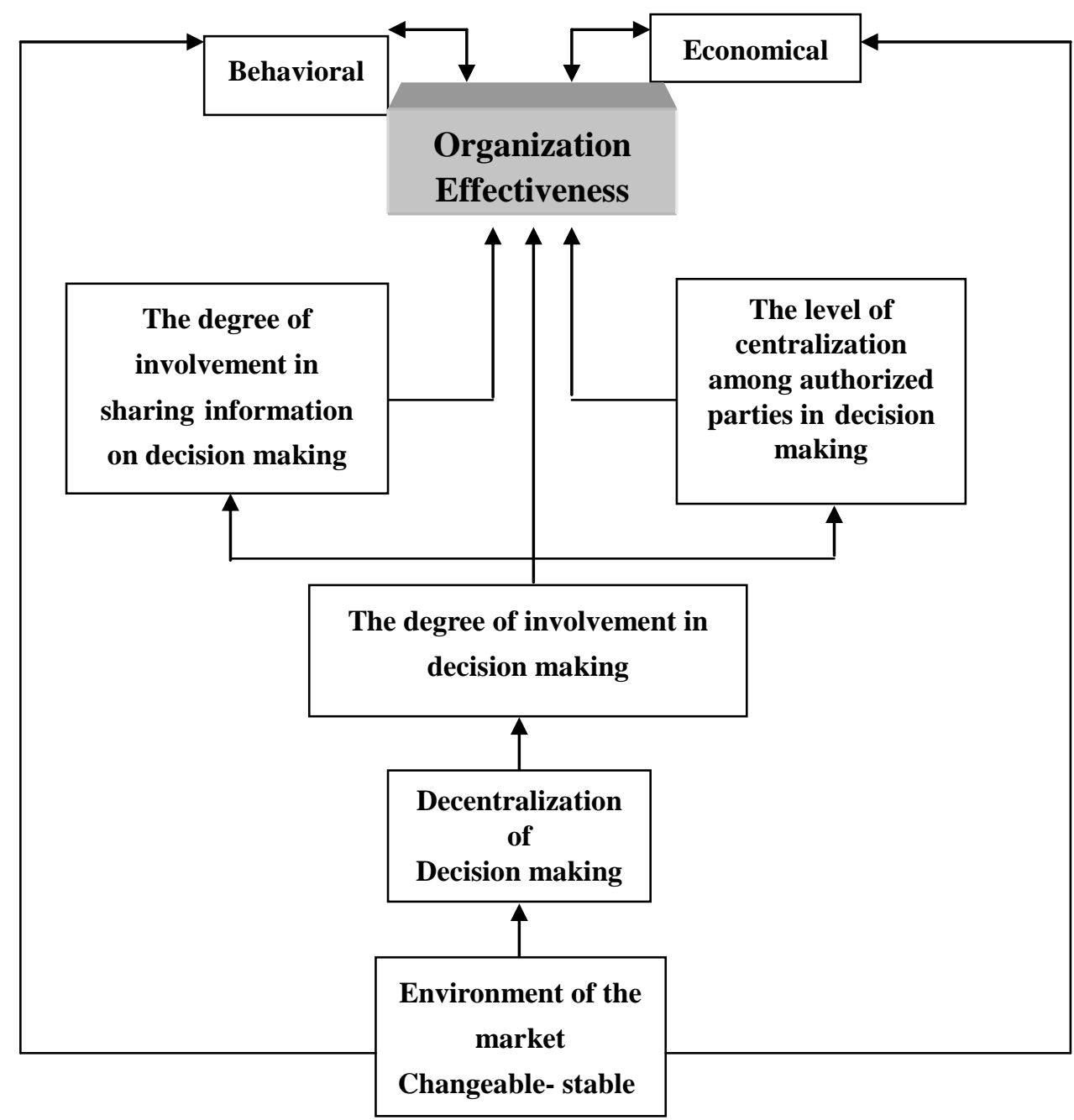

Figure 1. Research model

\section{Major Hypothesis}

\subsection{First Major Hypothesis}

Decentralization is directly related to the conditions of the market environment .Minor hypotheses can be derived from the major one:

First, the organization shows increased tendency towards employing decentralization of decision making especially decisions related to major management policies inside changeable market environments compared to stable ones.

Second, the organization shows increased tendency towards a high level of workers' involvement at different management levels in the process of strategic planning inside changeable market environments compared to stable ones.

Third, the organization shows increased tendency towards high level of involvement mainly in delivering data and information especially the information about the organization's key decisions (decisions regarding the policies and the plans of the organization) and distributing it to all management levels inside changeable market environments compared to stable ones.

\subsection{Second Major Hypothesis}

Co alignment level among decentralization of decision making process and the environment correlate incorporeally with the economical and behavioral effectiveness of the organization. The following minor hypotheses can be derived: 
First, there is a positive and incorporeal relationship between the effectiveness of the organization and the level of co alignment represented by both the decentralization of management policy decision making and the environment of the market.

Second, there is a positive and incorporeal relationship between the effectiveness of the organization and the level of co alignment presented by both the high involvement of workers in the process of decision making and environment of the market.

Third, there is a positive and incorporeal relationship between the effectiveness of the organization and the level of co alignment represented by both the high degree of involvement in information delivery and distributing it to different management levels and the environment of the market.

The researcher adopted the previous mentioned hypotheses following the contingency theory and other studies mentioned earlier particularly of Burns and Stalker (1961) Lawrence and Lorsch (1967) Negandhi and Reinmann (1972) and Azma and Mansfield (1981). It is worth mention here that the researcher could not find any relevant study conducted in the Arab States.

\section{Research Sample}

For the purpose of examining the study model and its hypotheses, the sample of the research encompassed a group of Jordanian organizations belonging to the industrial sector. The sample included 30 industrial organizations such as textiles, electricity, electronic industries, food and soda beverage and readymade clothes and other organizations that work in the field of building and construction. The main reason for choosing this sample of industrial organizations is that the study variables would be much clearer once used in industry than those used in other sectors such as services or commerce. In addition, the previous studies have applied the theory on industrial organizations and this study comes to be consistent with related literature using the same population of the study.

After identifying the sample of the study, 106 managers working in major managing directorates such as marketing, production, financing, human resources, planning and monitoring were selected.

The researcher conducted interviews and questionnaires which were distributed to the managers in the targeted organizations. The questions of the study were designed following the study of Negandhi and Reimann (1973) and Boseman and Jones (1974) as the first part of the questionnaire covered general information on the industrial organization such as the type of industry, the products produced, ownership and the number of workers. The second part of the questionnaire included questions on the environment of the market and the level of centralization of decision making where the criteria of Negandhi and Reimann was particularly adopted to design the questions related to the indicators of the organization's behavioral and economical effectiveness. It should be noted that present criteria were already employed in previous studies which reflects a high degree of validity and credibility as they were adopted in studying different organizations in India, Britain, Mexico and the USA. The researcher preferred to adopt the same criteria of the previous studies because he intended to compare the results of the present study with previous ones though there was a time interval between them. The researcher conducted a test on a small group of managers to examine the validity and credibility of the criteria. The questionnaire was also examined and inspected by a group of specialists to define the degree of clarity and reliability of the questions. Alpha coefficient for centralization, effectiveness and environment was calculated and they were $0.43,0.35$ and 0.67 respectively. Also, the correlation matrices were calculated as shown in table below

Table 1. Corrélation matrox for market environment

\begin{tabular}{lccc}
\hline Criteria $\backslash$ correlation coefficient & 1 & 2 & 3 \\
\hline Price competitiveness & 1 & - & - \\
Delay in delivering products to consumers & 0.21 & 1 & - \\
Availability of alternative products to consumers & 0.32 & $0.15-$ & 1 \\
\hline
\end{tabular}

Table 1 shows that there is a positive correlation between price competitiveness and the delay of delivering products to consumers as it scored (0.05) while there is a negative correlation between the availability of alternative products and the delay of delivering products to consumers, and this relationship is not the same significance. Table 2 shows the correlation matrix of criteria of centralization level in decision making. There are 
a set of negative correlations between the variables of centralized decision-making where correlation level ranges between 0.001 and 0.72 while some of these correlations have significance exceeding the level of 0.05 and some ones have no significance. There are also a set of negative correlations ranging between -0.02 and -0.61 and some ones have no significance, while others represent a level of 0.05 and less.

Table 2. Correlation matrix of centralization of decision-making

\begin{tabular}{|c|c|c|c|c|c|c|c|c|}
\hline Correlation Coefficients Measures & 1 & 2 & 3 & 4 & 5 & 6 & 7 & 8 \\
\hline Participation in main policies & 1 & & & & & & & \\
\hline Decisions on sales policy & 0.35 & 1 & & & & & & \\
\hline Decisions on marketing distributor & $0.2-$ & 0.19 & 1 & & & & & \\
\hline Decisions of determining product quantity and quality & 0.19 & $0.61-$ & 0.72 & 1 & & & & \\
\hline Decisions on planning the level of labor & 0.41 & 0.06 & 0.005 & 0.3 & 1 & & & \\
\hline Decisions of appointing managers of senior management & 0.28 & 0.26 & $0.04-$ & $0.16-$ & 0.38 & 1 & & \\
\hline Decisions of participation in strategic planning & 0.19 & 0.27 & $0.31-$ & 0.22 & 0.36 & 0.26 & 1 & \\
\hline Decisions of sharing information & 0.001 & 0.46 & 0.11 & 0.25 & 0.33 & 0.27 & 0.07 & 1 \\
\hline
\end{tabular}

Table 3 illustrates the correlation matrix of behavioral and economic effectiveness of organizations. There is a group of positive correlations ranging from $(0.03)$ to $(0.56)$, while others have significance of $(0.05)$ or more. There are negative correlations of effectiveness variables, some of which having significance of $(0.05)$ or more.

Table 3. Correlation matrix of the effectiveness of organizations

\begin{tabular}{|c|c|c|c|c|c|c|c|c|}
\hline Correlation Coefficients Measures & 1 & 2 & 3 & 4 & 5 & 6 & 7 & 8 \\
\hline The ability to maintain efficient labor & 1 & & & & & & & \\
\hline Morale and the extent of labor satisfaction & 0.39 & 1 & & & & & & \\
\hline The ability to control turnover and absence & 0.21 & 0.03 & 1 & & & & & \\
\hline $\begin{array}{l}\text { The ability to sustain strong relationships between persons in charge } \\
\text { and employees }\end{array}$ & 0.09 & 0.37 & 0.56 & 1 & & & & \\
\hline The ability to sustain relationships between departments & 0.37 & 0.11 & 0.52 & 0.05 & 1 & & & \\
\hline The ability to employ directors of senior management efficiently & 0.08 & 0.39 & 0.43 & 0.29 & 0.21 & 1 & & \\
\hline The rate of growth in sales & 0.07 & 0.44 & 0.26 & 0.12 & 0.49 & 0.17 & 1 & \\
\hline The rate of return on capital & 0.31 & 0.53 & 0.25 & 0.19 & 0.16 & 0.11 & 0.06 & 1 \\
\hline
\end{tabular}

\section{The Results of Research}

The study approved two major steps to illustrate the results. The first is to analyze the initial data of the study variables using frequency distributions and means for the questions of each criteria. The second involved the hypotheses of the study based on some significant statistics indicators, such as Pearson and Spearman correlation coefficient which are successfully used in such studies. These correlations show the relationship between the variables of the study.

\section{Data Analysis}

Table 4 shows the frequency distribution of director answers concerning market environment. They indicate that Jordan environment is deemed relatively stable. The stability of this indicator is due to the openness of Jordan market and the relative guidance of price policies. The average of the answers to this question was (1.77). In addition, the availability of competing alternatives to the product of the entity was stable too. The mean was (2.24) as well as the extent of delay to provide the product of which answers average was (2.16). 
Table 4. The frequency distributions of the market environment

\begin{tabular}{|c|c|c|c|c|c|c|c|}
\hline \multirow[t]{3}{*}{ Market Environment } & \multicolumn{6}{|c|}{ Market Nature } & \multirow[t]{3}{*}{ Mean } \\
\hline & \multicolumn{2}{|c|}{ Fierce competition } & \multicolumn{2}{|c|}{ Category average } & \multicolumn{2}{|c|}{ Possible competition } & \\
\hline & Freq. & $\%$ & Freq. & $\%$ & Freq. & $\%$ & \\
\hline Price competition & 23 & 22 & 36 & 34 & 47 & 44 & 1.77 \\
\hline The extent of delay to provide the product to consumers & 39 & 37 & 45 & 42 & 22 & 21 & 2.16 \\
\hline Availability of alternative products & 52 & 49 & 28 & 26 & 26 & 25 & 2.24 \\
\hline Total & 114 & 108 & 109 & 102 & 95 & 90 & 6.17 \\
\hline Mean & 38 & 36 & 36.3 & 13.4 & 31.6 & 30 & 2.05 \\
\hline
\end{tabular}

Table 4 shows the frequency distribution of director answers concerning the indicators of the centralization of decision-making. The mean was $(1.88-2.79)$ which means that there is high centralization in decision-making especially those related to major management policies, defining the production plan and the appointing the directors of senior and major management directors. The high centralization of Arab directors in general and Jordanian ones in specific is due to socialization were high centralization is exerted on children by parents, family or tribe, the fact which may be involuntary instilled into children to be practiced when they are in charge in positions of power, in addition to the fact that many companies are family ones.

Average participation in strategic decisions and long-term planning (2.14) is also high. This resulted in the poor participation of employees in such decisions and being exclusive to the senior management or other parties. On the other hand, the involvement of the various administrative levels in the information related to decisions was moderate as the mean was (1.88). This low mean may be due to the need of the administrative units for this information in order to perform their activities.

Table 5. Frequency distributions of centralization indicators

\begin{tabular}{|c|c|c|c|c|c|c|c|}
\hline \multirow{3}{*}{$\begin{array}{l}\text { Centralization indicators } \\
\text { Decisions of major management policies }\end{array}$} & \multicolumn{6}{|c|}{ Criteria of answers } & \multirow{3}{*}{\begin{tabular}{r|} 
Mean \\
\\
2.17 \\
\end{tabular}} \\
\hline & \multicolumn{2}{|c|}{$\begin{array}{c}\text { A committee of } \\
\text { directors of various } \\
\text { departments }\end{array}$} & \multicolumn{2}{|c|}{$\begin{array}{c}\text { Director general and } \\
\text { major department } \\
\text { director }\end{array}$} & \multicolumn{2}{|c|}{$\begin{array}{l}\text { Director general and } \\
\text { another party form } \\
\text { outside the entity }\end{array}$} & \\
\hline & 11 & 10 & 66 & 63 & 29 & 27 & \\
\hline Decisions of sales policies & 26 & 25 & 39 & 37 & 41 & 38 & 2.14 \\
\hline Decisions of marketing and production & 14 & 13 & 57 & 54 & 35 & 33 & 2.20 \\
\hline $\begin{array}{l}\text { Decisions of determining production quantity and } \\
\text { quality }\end{array}$ & 19 & 18 & 43 & 41 & 44 & 41 & 2.24 \\
\hline Decisions of planning policies & 30 & 28 & 37 & 35 & 39 & 37 & 2.08 \\
\hline $\begin{array}{l}\text { Decisions of appointing senior management } \\
\text { directors }\end{array}$ & 6 & 6 & 10 & 9 & 90 & 85 & 2.79 \\
\hline $\begin{array}{l}\text { Decisions of information sharing between the } \\
\text { various management levels }\end{array}$ & 46 & 44 & 27 & 25 & 33 & 31 & 1.88 \\
\hline Decisions of participation on strategic planning & 28 & 26 & 35 & 33 & 47 & 41 & 2.24 \\
\hline Total & 180 & 170 & 314 & 297 & 254 & 277 & 17.64 \\
\hline Mean & 22.5 & 21.25 & 39.25 & 37.17 & 44.25 & 41.63 & 2.20 \\
\hline
\end{tabular}

As to the effectiveness of the organization in both behavioral and economic respects, they were illustrated in Table 6 indicating that there is relative cooperation in behavioral and economic effectiveness of the organization. The answers of directors show that the ability of the organization to maintain efficient labor and to keep strong relationships amongst the departments thereof was relatively high, where the mean of director answers is (1.421.69). The indicator of economic effectiveness was consistent with these indicators. The mean of the growth of sales and the return on capital was (1.32) and (1.84), respectively. Meanwhile the behavioral effectiveness of the 
organization was low, and so was the ability of the organization to sustain morale of labor, appointing efficient directors and decreasing work and absence turnover. In general, the indicators of behavioral effectiveness were inconsistent to each other due to the variation in interest of the departments in Jordanian economic organizations in the concerned staff, as is obvious in return on capital which is relatively low due to the nature of economic philosophy adopted by the management of organizations that highly affects the trends of the sample organizations.

Table 6. Frequency distributions of the indicators of behavioral and economic effectiveness

\begin{tabular}{|c|c|c|c|c|c|c|c|}
\hline \multirow[t]{3}{*}{ Effectiveness indicators } & \multicolumn{6}{|c|}{ Criteria of answers } & \multirow[t]{3}{*}{ Mean } \\
\hline & \multicolumn{2}{|c|}{1} & \multicolumn{2}{|c|}{2} & \multicolumn{2}{|c|}{3} & \\
\hline & Freq. & $\%$ & Freq. & $\%$ & Freq. & $\%$ & \\
\hline The ability to maintain efficient labor & 77 & 73 & 13 & 12 & 16 & 15 & 1.42 \\
\hline Morale and the extent of labor satisfaction & 35 & 33 & 26 & 25 & 45 & 42 & 2.09 \\
\hline $\begin{array}{l}\text { The ability to sustain strong relationships between persons in } \\
\text { charge and employees }\end{array}$ & 46 & 43 & 22 & 21 & 38 & 36 & 1.92 \\
\hline The ability to control turnover and absence & 48 & 46 & 29 & 27 & 39 & 37 & 2.20 \\
\hline The ability to sustain relationships between departments & 59 & 56 & 21 & 20 & 26 & 24 & 1.69 \\
\hline $\begin{array}{l}\text { The ability to employ directors of senior management } \\
\text { efficiently }\end{array}$ & 32 & 30 & 33 & 31 & 31 & 29 & 1.80 \\
\hline The rate of growth in sales & 83 & 78 & 12 & 11 & 11 & 10 & 1.32 \\
\hline The rate of return on capital & 43 & 41 & 37 & 35 & 16 & 24 & 1.84 \\
\hline Total & 423 & 400 & 193 & 18 & 232 & 217 & 4.28 \\
\hline Mean & 52.8 & 50 & 24.1 & 22.7 & 29 & 27.1 & 1.7 \\
\hline
\end{tabular}

\section{Test of Hypotheses}

Pearson correlation coefficient was calculated by measuring the strength of relationship between centralization and market environment of Jordan, noting that the study supposed that there is inverse relationship between the level of centralization and market environment. The more the environment is stable, the more the organization trends towards centralization are, and vice versa. Table 7 shows Pearson Correlation Coefficient and significance test concerning the environment and centralization. The said table indicates that there is a strong direct relation between the level of decision centralization and market environment. This relation was significance level (0.59) which indicates that the increase in the level of centralization in decision making related to the major management policies and others when the organization encounters high-changing market environment. Through the field observation of the researcher, it is obvious that such a relation may be true in the industrial organizations due to most of them being family ones.

Table 7. The relation between centralization and market environment

\begin{tabular}{lc}
\hline Indicators of centralization & Market environment \\
\hline Centralization of decisions & 0.59 \\
Decision sharing & -0.06 \\
Participation in information division & -0.33 \\
Total centralization indicator & 0.21 \\
\hline
\end{tabular}

As to practical respect, this relation indicates the weakness of the ability of the organizations being studied to change their organizational structure to be consistent with the nature of market environment they are experiencing. This result does not correlate with the method of Contingency Theory stating the increase of decentralization in the changing environment which was supported by its leading pioneers such as Burns and Stalker (1961) and Lawrence and Lorsch (1967) as well as does not support the current hypothesis of research. 
Table 8 . The relation between decentralization and the effectiveness of the organization

\begin{tabular}{lccc}
\hline & \multicolumn{3}{c}{ Effectiveness of the organization } \\
\cline { 2 - 4 } Indicators of centralization & Behavioral & Economic & Total Effectiveness \\
\hline Centralization of decisions & 0.26 & -0.33 & 0.35 \\
Decision sharing & -0.17 & 0.22 & 0.25 \\
Participation in information division & -0.37 & 0.43 & 0.18 \\
Total centralization indicator & -0.33 & 0.21 & 0.29 \\
\hline
\end{tabular}

Sample size $=70$ directors.

Table 8 indicates the increase in total effectiveness of the organization while tending to high centralization in decision making, but the relation between centralization and behavioral centralization was negative (correlation coefficient $=-0.33$, significance 0.01 ). when considering the relations between sub-indicators of centralization and the behavioral and economic effectiveness, it is found that there is a significant positive correlation between the power of decision making and the behavioral effectiveness (correlation coefficient $=0.29$ significance 0.01 ). As to the relation between participation in decision making and the economic effectiveness and some of these correlations is not significant particularly the correlation between participation and economic effectiveness. There is a negative correlation between participation in information division and participation in information with the behavioral effectiveness, indicating the increase in the effectiveness of the organization in achieving its goals related to decreasing the rate of turnover and absence, raising morale of workers, maintaining a strong relationship amongst colleagues, directors and departments when increasing participation in decisions and dividing information between the various levels of management. For the purpose of testing adaptation hypotheses indicated previous part of this study, Spearman rank correlation coefficient of the two samples was calculated.

As to the relationship between the indicators of centralization and effectiveness, as shown in Table (9), the study supposed there is a significant correlation between co-alignment of decentralization with environment and the effectiveness of the organization, and by considering Table 9, it was found that there is a significant positive relationship between total centralization indicator and total effectiveness (correlation coefficient $=0.38$, significance 0.01) under the stable environment and there is a non-significant negative correlation $(-0.19)$ between the effectiveness of the organization and the total centralization indicator under the changing market environment. This supports the major hypothesis of the research of contingent co-alignment between the degree of centralization and effectiveness under the various market circumstances. This relationship means that the total tendency of organizations working in dynamic changing environments is increased towards decentralization in decision making, leading to increasing their total effectiveness in achieving their goals while the organizations working in stable environment tend to increase the centralization of decision making to achieve their goals. This result in its content correlates with the Contingency Theory and studies of Lawrence and Lorch (1967) and Burns and Stalker (1961) as well as partially correlates with the studies of Negandhi and Reiman (1972) in India and Boseman and Jones (1974) in Mexico.

Table 9. The relationship between centralization and effectiveness under the changing and stable market environment

\begin{tabular}{|c|c|c|c|c|c|c|}
\hline \multirow{2}{*}{ Centralized Indicators } & \multicolumn{3}{|c|}{$\begin{array}{l}\text { Stable market environment } \\
\text { Sample }=40 \text { directors }\end{array}$} & \multicolumn{3}{|c|}{$\begin{array}{l}\text { Changing market environment } \\
\text { Sample }=30 \text { directors }\end{array}$} \\
\hline & $\begin{array}{l}\text { Behavioral } \\
\text { effectiveness }\end{array}$ & $\begin{array}{c}\text { Economic } \\
\text { effectiveness }\end{array}$ & $\begin{array}{c}\text { Total } \\
\text { effectiveness }\end{array}$ & $\begin{array}{l}\text { Behavioral } \\
\text { effectiveness }\end{array}$ & $\begin{array}{c}\text { Economic } \\
\text { effectiveness }\end{array}$ & $\begin{array}{c}\text { Total } \\
\text { effectiveness }\end{array}$ \\
\hline Centralization of decisions & 0.25 & 0.16 & 0.37 & 0.04 & 0.48 & $0.32-$ \\
\hline Participation in decisions & $0.31-$ & 0.56 & 0.23 & 0.19 & 0.37 & 0.26 \\
\hline Participation in information division & $0.21-$ & 0.41 & 0.36 & $0.27-$ & 0.05 & 0.31 \\
\hline Total centralization & $0.17-$ & .0 .21 & 0.38 & $0.46-$ & 0.11 & 0.19 \\
\hline
\end{tabular}

Size of 1 st sample $=40$ directors, size of 2 nd sample -30 directors. 
The hypothesis of the first sub-study indicated a strong relationship between alignment of the relationship of major decision centralization and environment with the effectiveness of the organization. By testing the correlation coefficients mentioned in the table above, it was found that there is a positive correlation between the degree of decision centralization and the total effectiveness of the organization in light of the stable circumstances of market environment, and a negative correlation concerning the same relationship in the changing environment, supporting the hypothesis of the indicated study. Table 9 shows that there a positive relationship between the degree of decision centralization and the behavioral and economic effectiveness. The correlation coefficient between economic effectiveness and the degree of decision centralization was insignificant. Consequently, the trend of these relationships indicates that the organizations tend to centralize decision making in the stable market environments to increase their behavioral and economic effectiveness, while under the changing circumstances of market environment, the relationship between the indicator of behavioral effectiveness and the degree of centralization was weak and insignificant, and the relationship between the economic effectiveness and the degree of centralization was strong, positive and significant, where this relationship indicates that the organizations working in changing market environment tend to increase the degree of centralized decision making to increase its effectiveness. Such an interpretation is deemed acceptable under Jordan environment characterized with openness. This result does not correlate with the results of previous studies specially Negandhi and Reimann (1972) and Boseman and Jones (1974) while partially correlates with Azma and Mansfield (1981) in UK Wales which refused the core of Contingency method indicating that it is an inaccurate method.

The study also supposed that there is a relationship between participation in decision making and effectiveness under the changing and stable market environment. The results shown in Table 9 indicate that this relationship has been partially proven regarding the changing environment, and more specifically the study indicated that there is a positive relationship between participation in decision making and effectiveness. Although this relationship is insignificant, it indicates that the organizations facing stable market environment tend to reduce the degree of workers participation in decision making in the manner that leads to increasing its effectiveness but this fact has not appeared in measuring the relationship between participation and behavioral effectiveness where correlation was negative and significant at level of (0.05). this relationship indicates the decrease in the effectiveness of the organization when increasing the degree of participation in decision making under the stable market environment and the relationship between participation and the economic effectiveness was positive, relatively high and significant of (0.001) which supports the position of the study hypothesis and also relatively supports the study of Negandhi and Reimann (1972).

When observing the relationships of the organizations working in a changing market environment, it was found that there is a significant positive correlation between the degree of participation in decision making and economic effectiveness, and a negative correlation between the first indicator and the behavioral effectiveness $(-0.19)$ but this correlation is insignificant which proves that this hypothesis was partially assigned by economic effectiveness and the degree of participation under the stable environment and the relationship between participation and behavioral effectiveness in the changing environment.

The final hypothesis of the study indicated that there is a relationship between the degree of participation in information and effectiveness under the circumstances of the changing and stable market environment. The results of correlation analysis supported this relationship through a positive significant correlation of $(0.36)$ for the stable environment, and a positive correlation of $(0.31)$ for the changing environment. This relation proves that the degree of participation in decision making is related to the organization effectiveness according to the indicators of environment in which the organization works, the fact that supports the core of the studies: Burns and Stalker (1961) Lawrence and Lorsch (1967) and partially Negandhi and Reimann (1972).

Table 10 provides a summary of the results of the study hypothesis. It was found that there are two hypotheses that were completely proved and three that are partially proved by the relationship between the behavioral and economic effectiveness of the organization with the three indicators of centralization. 
Table 10. The results of testing the hypotheses of research

\begin{tabular}{lll}
\hline Hypothesis & Relationship between environment, centralization and effectiveness & Result of test \\
\hline 1st major hypothesis / 1 & $\begin{array}{l}\text { The relationship between the degree of centralization in decisions and } \\
\text { market environment }\end{array}$ & Hypothesis not proved \\
1st major hypothesis / 2 & The relationship between participation in decisions and market environment & Hypothesis partially proved \\
1st major hypothesis / 3 & The relationship between sharing information and market environment & Hypothesis proved \\
2nd major hypothesis / 1 & $\begin{array}{l}\text { The relationship between organization effectiveness and organizational } \\
\text { adaptation of the relationship between the degree of decision centralization } \\
\text { and market environment }\end{array}$ & \\
2nd major hypothesis / 2 & $\begin{array}{l}\text { The relationship between organization effectiveness and organizational } \\
\text { adaptation of the relationship between the participation of workers and } \\
\text { market environment }\end{array}$ & Hypothesis partially proved \\
2nd major hypothesis / 3 & $\begin{array}{l}\text { The relationship between organization effectiveness and organizational } \\
\text { adaptation of the relationship between sharing workers in information and } \\
\text { market environment }\end{array}$ & \\
\hline
\end{tabular}

This indicates that the core of Contingency Theory can be valid and applicable in the circumstances of cultural and economic variation, the degree of technological development and the political philosophy that distinguishes the developing countries from the developed ones. However, this research supports the contradiction between the results of this study and the previous ones regarding the partial relationships between centralization and the indicators behavioral and economic effectiveness of the organization. This may lead to supporting the conclusion reported by Negandhi and Reimann (1972) in a study of the Indian organizations which proves that contingency method needs adjustment when applied in the developing countries, where this adjustment takes the cultural and economic factors of the developing countries into consideration.

\section{Results}

This study targeted testing contingency relationship between effectiveness - market environment and centralization of decision making. The results illustrated that contingency method concerning studying this relationship is valid to some extent by proving some hypotheses of the research. This proves that the market environment decision makers recognizing whether stable or changing increases the effectiveness of its organizations in achieving their goals. This is performed by determining the extent of the centralization of decision making based on the type of environment as the degree of authorization determines the ability of decision makers to practice the effectiveness of coordination and control upon the activities of the organization and trying to reconcile these activities to serve the goals of the organization.

This research concluded that there are some contradictions and differences between its current results and the results of previous studies, particularly Azma and Mansfield (1981) in South Wales/UK, which requires reconsideration in Contingency Theory and trying to set a reconciling formulation that makes it appropriate for the current status of environment and observing the ecology and culture factors of both developing and developed countries.

\section{Recommendations}

By the relative proof of research hypotheses, the study recommends increasing the awareness of directors to the circumstances of market environment they are working in so that the decisions related to the administrative structure and the other organizational operations are consistent with those circumstances, since the organizations of the study significantly contribute in GNP of Jordan.

This study also recommends the importance of expanding the range of applying Contingency Theory in other experimental studies involving the market environment of Jordan as well as the environment of the Arab World in order to illustrate the impact of cultural and economic factors distinguishing those countries for others, as this helps enroot the idea of Contingency Theory and enrich the research literature of studying organizations.

\section{References}

Azma, M., \& Roger, M. (1981). Market conditions centralization and organizational effectiveness contingency theory reconsidered. Human Relations Journal, 34(2), 157-168. 
http://dx.doi.org/10.1177/001872678103400205

Bennis, A. G. (1966). The concept of organizational health in W.G Bennis: Changing organization. New York: McGraw Hill.

Blau, P. M. (1967). Exchange and power in social life. New York: Wiley.

Bosemen, F. G., \& Jones, R. E. (n.d.). Market conditions, decentralization and organizational effectiveness. Human Relations Journal, 27(7), 665-676.

Burns, F., \& Stalker, G. W. (1961). The management of Innovation. London: Tavistok.

Camppell, J. P. (1977). On the Nature of Organizational effectiveness. In P. S. Goodman \& J. M. Pennings (Eds.), New perspectives on organizational effectiveness. San Francisco: JosseyBass.

Child, J. (1975). Managerial and organizational factors associated with company performance. Journal of Management Studies, 11(1), 175-189.

Child, J. (1977). Organizations, structure and processes. H.J: prentic- Hall.

Child, J. (1984). Organization a guide to problems and practice. London: Harper and Row. http://dx.doi.org/10.4135/9781446280348

Dill, N. K. (1958). Environment as an influence on managerial autonomy. Administrative Science Quarterly, 2, 409-443. http://dx.doi.org/10.2307/2390794

Duncan, R. (1972). Characteristics of organizational environment and perceived environmental uncertainty. Administrative science Quarterly, 17, 313-327. http://dx.doi.org/10.2307/2392145

Emerson, R. K. (1962). Power-dependence relations. American Sociological Review, 27, 31-40. http://dx.doi.org/10.2307/2089716

Emery, F. E., \& Trist, E. L. (1965). The causal texture of organizational environments. Human Relations Journal, 18(1), 21-32. http://dx.doi.org/10.1177/001872676501800103

Etzioni, A. (1972). The structuring of organizations: A synthesis of the research. N.J: Prentice.

Etzioni, A. A. (1964). Modern organization. New Jersey: DrenticHill.

Hall, R. H. (1977). Organization: Structure and processes (2nd ed.). Englwood Cliffs, H.J: Prentice-Hall.

Heg, et al. (1972). A contingency theory of organizations: Re-examined in the context of developing country. Academy of management Journal, 15, 137-146. http://dx.doi.org/10.2307/254904

Lawewnce, P. R., \& Lorsch, J. W. (1967). Organization and environment. Cambridge Mass: Harvard University Press.

Mansfield, K. (1986). Company strategy and organizational Design. London: Croom Helm.

Miles, R. H. (1980). Macro organizational behavior. Santa Monica: Cal Goodyear.

Negandhi, A. R., \& Prasad. (1971). Comparative management. John Wiley and sons, Inc.

Negandhi, A. R., \& Reimann, B. C. (1973). Task environment, decentralization and organizational effectiveness. Human Relations Journal, 26, 203-214. http://dx.doi.org/10.1177/001872677302600206

Pennings, J. M. (1975). The relevance of the structural contingency model for organizational effectiveness. Administrative Science Quarterly, 20, 393-410. http://dx.doi.org/10.2307/2391999

Pfeffer, J., \& Leblebici, H. (1973). The effect of competition on some dimension of organizational structure. Social Forces, 52, 268-279. http://dx.doi.org/10.1093/sf/52.2.268

Reeley, M. (1978). A social justice approach to organizational evaluation. Administrative Sciences Quarterly, 22, 272-292.

Reimann, B. C. (1976). Task environment and decentralization: A cross-national replication. Human Relations, $27(7), 684$.

Streers, R. M. (1977). Organizational effectiveness: A behavioral view. Santa Monica: Good year press.

Thompson, J. D. (1967). Organization in Action. New York: McGraw-Hill.

Weber. (1947). The theory of social and economic organization. Fair Lawn: Oxford university press. 


\section{Copyrights}

Copyright for this article is retained by the author(s), with first publication rights granted to the journal.

This is an open-access article distributed under the terms and conditions of the Creative Commons Attribution license (http://creativecommons.org/licenses/by/3.0/). 